\title{
Impact of cattle on the prevalence and severity of trachoma
}

\author{
G DE SOLE \\ National Programme for the Prevention of Blindness
}

SUMmARY Ethiopia is the African country with the largest number of cattle (26 million). Because of the potential impact of cattle on the transmission and severity of trachoma, the major cause of blindness in the country, an attempt is made to document this association to justify the inclusion of the control of cattle pollution in the prevention of blindness. The prevalence of trachoma is lower in pastoralists who herd mainly camels than in pastoralists who herd mainly cattle. In the first group the prevalences of moderate and severe trachoma in children under 10 are $0.9 \%$ and trichiasis/entropion in the total population $0 \cdot 2 \%$, whereas in the second group the prevalences are $45 \cdot 1 \%$ and $4.0 \%$ respectively. In Borana pastoralists with and without cattle the prevalence ratio for moderate and severe trachoma is 1.0 , whereas the prevalence ratios for severe trachoma and conjunctivitis were higher in the group with cattle, 2.5 and $3.0(\mathrm{p}<0.001$ for both). The elimination of cattle pollution should reduce the prevalence of severe trachoma by $45 \cdot 4 \%$. This is the first study presenting evidence of an association between cattle and trachoma. On the basis of this study a strong recommendation is made to the Ministry of Health to control cattle pollution in rural areas as a major strategy to prevent blindness in Ethiopia.

With an estimated prevalence of $0.7 \%$ blind in the
total population, trachoma is the major cause of
blindness in Ethiopia.' Cattle droppings, by exacer-
bating this problem, are believed to be associated
with blinding trachoma. However, hard evidence has
been lacking. Other domestic animals do not seem to
play an appreciable part in the transmission of the
disease. Droppings from goats and sheep are too
small and dry. Transport animals are too few. Camel
herds roam far from villages under the care of a few
adults.
The Ethiopian Ministry of Health is strongly
committed to improving sanitation in rural areas.
However, it concentrates on latrine building. It is the
belief of the author that in rural areas of Ethiopia
control of pollution created by 26 million cattle ${ }^{2}$
would be more effective than constructing latrines for
the prevention of blindness caused by trachoma.
The following two studies were conducted to
collect data supporting this opinion: (1) a comparison

Correspondence to G De Sole, MD, OMS-ONCHO, BP 549, Ouagadougou, Burkina Faso, West Africa. of the prevalence of trachoma in pastoralists who mainly herd cattle and pastoralists who mainly herd camels; (2) a comparison of the prevalence of trachoma and conjunctivitis in the same pastoralist group, selecting one village with cattle and one that had lost its cattle in the recent drought.

\section{Materials and methods}

The decision to study Cuscitic pastoralist groups was based on the high degree of homogeneity of this population. The three groups surveyed live in similar dry environments where pastoralist life is the only answer to successful survival if outside intervention is excluded. Pastoralist life itself does not allow much variation because of the harshness of the environment. Mobility is controlled by rain. Yearly variation of the rainfall is more important than variation between places. The three groups were all Moslem and lived in areas with two rainy seasons per year, averaging an annual precipitation of $400 \mathrm{~mm}$.

For the first study Somali people from the Hiran region of Somalia were chosen to represent camel 
herders. They also keep a few cattle, less than one per family. A total of nine villages were randomly selected from the list prepared by the smallpox eradication campaign. Kereyu and Borana from Shewa and Sidamo regions of Ethiopia were chosen as cattle herders. Both groups also have small camel herds. A total of 19 Kereyu villages located in a $20 \mathrm{~km}$ radius from the town of Metahara were selected. Only four Borana villages were selected, two in the east and two in the centre of their territory. The only other Cuscitic pastoralist group in Ethiopia, the Afar, was excluded because the Afars live in an ecologically different environment. The average size of the Somali villages was 24 children under the age of 10 per village. The average size of the Kereyu villages was 48 children under the age of 10 per village. The average size of the Borana villages was 206 children under the age of 10 per village.

To decrease the possible influence of factors not accounted for it was considered important to compare prevalences in the same ethnic group between villages with and without cattle. The present drought made this study possible. Two Borana villages of approximately the same size, 210 and 197 children under the age of 10 , were selected. They are located in the central area of the Borana territory, the first with cattle near the town of Yabello, and the second without cattle near the town of Mega. The latter village was formed two years ago by families who had lost their herds. All families present had been living in the village for at least seven months. Both villages were surveyed, two days apart, at the beginning of the small rainy season. Characteristics of the two villages are given in Table 2 . In all villages of the two studies the entire population under the age of 10 was examined. For the diagnosis of trachoma and conjunctivitis the 1981 WHO criteria were followed. ${ }^{3}$ These are:

Moderate trachoma: more than 5 follicles in the central tarsal plate (equivalent to WHO follicles grade F3).

Severe trachoma: papillae obscuring more than half the tarsal vessels plus follicles (equivalent to WHO papillae grade $\mathrm{P} 3$ and follicles grade $\mathrm{F} 1$ to F3).

Conjunctivitis: hyperaemia, purulent or mucoid discharge, frequent swelling of the lids and periorbital area.

\section{Results}

In Somali camel herders the prevalence of moderate and severe trachoma in children under 10 was $0.9 \%$, and the prevalence of trichiasis/entropion in the total population $0 \cdot 2 \%$. These figures are below the cut-off points for hyperendemicity of $5 \%$ and $1 \%$ estab-
Table 1 Prevalence of trachoma in three pastoralist groups: mainly Somali camel herders and mainly Kereyu and Borana cattle herders

\begin{tabular}{lcc}
\hline & $\begin{array}{l}\text { Moderate }+ \text { severe trachoma } \\
\text { in children under } 10\end{array}$ & $\begin{array}{l}\text { Trichiasis/entropion } \\
\text { in total population }\end{array}$ \\
\hline Somali & $2 / 216(0 \cdot 9 \%)$ & $1 / 499(0 \cdot 2 \%)$ \\
Kereyu & $349 / 907(38 \cdot 5 \%)$ & $82 / 2056(4 \cdot 0 \%)$ \\
Borana & $427 / 825(51 \cdot 8 \%)$ & - \\
\hline
\end{tabular}

lished by the WHO. ${ }^{3}$ The prevalence of moderate and severe trachoma was $38.5 \%$ in Kereyu and $51.8 \%$ in Borana cattle herders. The prevalence of trichiasis/entropion in the total population was $4.0 \%$ in Kereyu people. No trichiasis/entropion data were collected for Borana people (Table 1). The difference between prevalences in camel and cattle herders was statistically significant $(p<0 \cdot 001)$. In the 19 Kereyu villages surveyed, village size presented a statistically insignificant negative correlation of -0.0168 with prevalence of moderate and severe trachoma (Figure 1).

Table 2 depicts the prevalence of eye infections in Borana pastoralists with and without cattle. The prevalence of moderate and severe trachoma in children under 10 was $52.3 \%$ in the village with cattle and $53.3 \%$ in the village without cattle. The ratio of trachoma prevalences was $1 \cdot 0$. However the prevalences of severe trachoma and conjunctivitis were higher in the village with cattle, $29.9 \%$ and $15.2 \%$ respectively, than in the village without cattle, $15 \cdot 2 \%$ and $5.0 \%$. The prevalence ratio for severe trachoma

Table 2 Characteristics of the Borana villages

\begin{tabular}{|c|c|c|c|}
\hline & $\begin{array}{l}\text { Village with } \\
\text { cattle }\end{array}$ & $\begin{array}{l}\text { Village without } \\
\text { cattle }\end{array}$ & $\begin{array}{l}\text { Prevalence } \\
\text { ratio }\end{array}$ \\
\hline $\begin{array}{l}\text { Size (no. of children } \\
\text { under 10) }\end{array}$ & 197 & 210 & \\
\hline Source of water & well & well & \\
\hline Distance to water & $<1 \mathrm{~km}$ & $<1 \mathrm{~km}$ & \\
\hline Housing & $\begin{array}{l}\text { Round huts, } \\
\text { no windows }\end{array}$ & $\begin{array}{l}\text { Round huts, } \\
\text { no windows }\end{array}$ & \\
\hline $\begin{array}{l}\text { Average shortest } \\
\text { distance between } \\
\text { houses }\end{array}$ & $3 \mathrm{~m}$ & $3 \mathrm{~m}$ & \\
\hline Ethnic groups & Borano & Borano & \\
\hline Nearest health centre & $13 \mathrm{kms}$ & $15 \mathrm{kms}$ & \\
\hline $\begin{array}{l}\text { Proportion of children } \\
\text { examined with flies } \\
\text { in eyes out of total } \\
\text { examined }\end{array}$ & $3 / 4(75 \%)$ & $1 / 5(20 \%)$ & \\
\hline $\begin{array}{l}\text { No. of children under } \\
10 \text { examined }\end{array}$ & 197 & 210 & \\
\hline $\begin{array}{l}\text { Moderate }+ \text { severe } \\
\text { trachoma }\end{array}$ & $103(52 \cdot 3 \%)$ & $112(53 \cdot 3 \%)$ & $1 \cdot 0$ \\
\hline Severe trachoma & $59(29.9 \%)$ & $25(11 \cdot 9 \%)$ & $\begin{array}{l}2.5 \\
\quad(p<0.001)\end{array}$ \\
\hline Conjunctivitis & $30(15 \cdot 2 \%)$ & $10(5 \cdot 0 \%)$ & $\begin{array}{l}3.0 \\
\quad(p<0.001)\end{array}$ \\
\hline
\end{tabular}




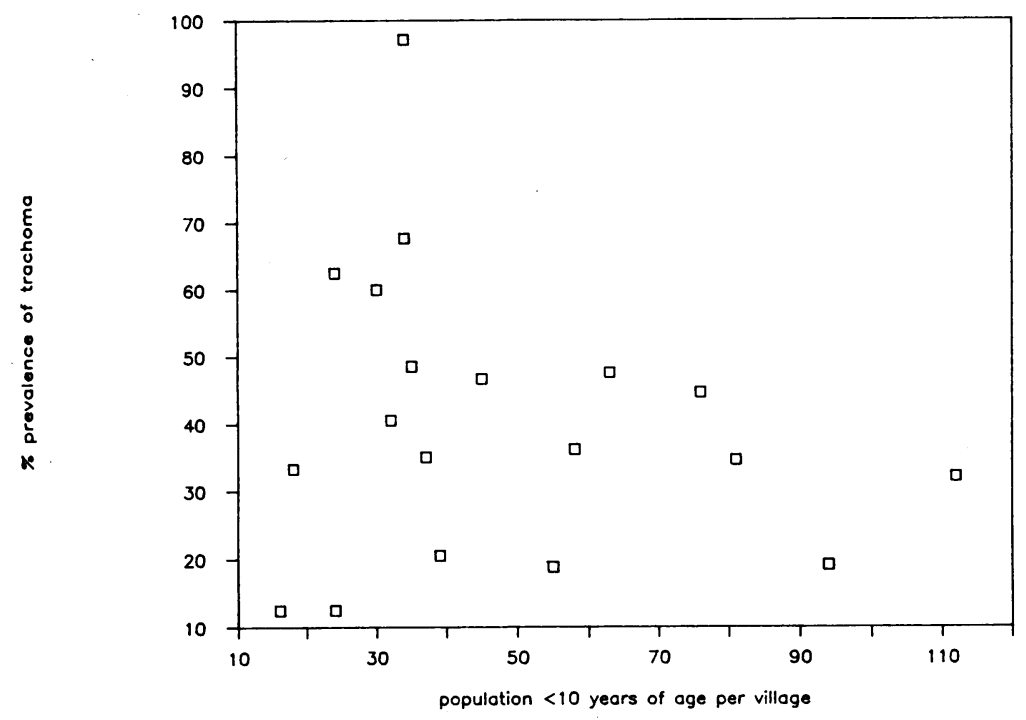

Fig. 1 Prevalence of moderate and severe trachoma in children under 10 and community size in Kereyu cattle herders.

was $2 \cdot 5(\mathrm{p}<0 \cdot 001)$. The prevalence ratio for conjunctivitis was $3 \cdot 0(\mathrm{p}<0.001)$.

\section{Discussion}

The three Cuscitic pastoralist groups were chosen because of the homogeneity of their ecological environment and ways of life. The prevalence of trachoma is several times higher in cattle herder pastoralists than in camel herders. The disease is the major cause of blindness in the former group whereas it does not constitute a public health problem in the latter. Seasonality may account for part of the observed difference of active trachoma but does not influence the higher prevalence of trichiasis/ entropion. In addition, on the assumption that the data on Somali people were collected during the month of lowest incidence, the $0.9 \%$ moderate and severe trachoma prevalence recorded can be compared with the lowest prevalence recorded in the survey of Kereyu people. The survey was conducted during three distinct periods before, during, and after the main rainy season. The lowest prevalence of $23.9 \%$ was recorded before the rains. It is 26 times greater than that of the Somali sample. Village size does not appear to influence the observed difference in prevalence. A statistically insignificant negative correlation was found in the Kereyu villages between prevalence and village size. The correlation coefficient was not calculated in the other two ethnic groups because of the small number of villages or low prevalence.

The second study indicates that there is an increased risk of severe trachoma (prevalence ratio
2.5) and conjunctivitis (prevalence ratio 3.0) when cattle are present. However, the presence of moderate and severe trachoma (prevalence ratio 1.0) remains uninfluenced. The high prevalence of active trachoma in the group without cattle is explained by the fact that they lost their herds only recently. For the same reason the difference in prevalence of severe trachoma and conjunctivitis reported may be considered an underestimate if their prevalence is expected to decrease in the group without cattle with prolonged lack of exposure to this risk factor.

However, it should be emphasised that the association described in this paper may not be entirely causal, but at least in part due to a confounding phenomenon.

These studies demonstrate the importance of cattle in the transmission and severity of eye infections. Even though the Tric agent infection alone can cause hyperendemic trachoma, it seems that bacterial infection is required in addition to give rise to blinding hyperendemic trachoma. ${ }^{4}$ This condition arises when eye-to-eye transmission is frequent in a situation of extreme ocular promiscuity, with flies adding to the spread of the disease. ${ }^{4}$ Cattle droppings, by increasing the number of flies, contribute to the transmission of blinding trachoma, as the increased risk of severe trachoma and conjunctivitis in this study indicates. Flies were seen on children's faces during the examinations far more often in the villages with cattle ( 3 out of four) than in the villages without (one out of five).

It appears, however, that neither cattle ownership not the presence of cattle in the village has a major role in the size of the fly population. Instead, the 
major determinant seems to be the way in which the cattle are kept. In the Borana village with cattle each family kept his herd in a corral about $7 \mathrm{~m}$ in diameter attached to the living quarters, from sunset to sunrise. The corrals were filled with droppings and flies were swarming. The low level of personal hygiene of the children worsened the situation. Flies were attracted by eye discharge and were allowed on the children's faces for several seconds, increasing the probability of carrying the infection to susceptible individuals.

This vicious cycle appears to be characteristic of children up to the age of 12 years. Persons over this age clean their faces regularly and wave flies away from their eyes. Cattle pollution and this vicious circle are not restricted to pastoralists, who constitute only a small percentage of the Ethiopian population, but are common for the majority of the mainly farming rural population of the country. On an estimate that $55 \%$ of the Ethiopian population is exposed to cattle pollution, the elimination of this factor would reduce the prevalence of severe trachoma lesions by $45 \cdot 4 \%$.

On the basis of these findings a strong recommendation is made to the Ministry of Health to include control of cattle pollution, in addition to promoting improved personal hygiene $e^{5}$ especially of children under 12, to prevent blindness in rural areas. The construction of corrals distant from living quarters is suggested. Because of the programme of village construction in the country, it would be preferable to start implementing this strategy in the new settlements and attempt to modify old villages at a later date. Its implementation will also create conditions for prospective studies on the subject.

We are grateful to the Yaebello, Mega, and Metahara health centres for their kind collaboration.

\section{References}

1 Budden FH. Blindness in Ethiopia report. Geneva: WHO, STC, 1981.

2 Ethiopian Ministry of Agriculture. Annual report. Addis Ababa: Government Office, 1984.

3 Dowson C, Tarizzo ML. Guide to trachoma control. Geneva, WHO: 1981.

4 Jones BR. The prevention of blindness from trachoma. Trans Ophthalmol Soc UK 1975; 95: 16-32.

5 Taylor HR, Velasio FM, Sommer A. The ecology of trachoma: an epidemiological study in Southern Mexico. Bull WHO 1985; 63: 559.

Accepted for publication 31 October 1986. 